\title{
120 Jahre ATZ
}

Liebe Leserin, lieber Leser,

das Riesenrad im Wiener Prater hat es 2017 geschafft, der Autobau bei Opel ist 2019 dran: Dieses Jahr, 2018, feiert die ATZ ihr 120-jähriges Bestehen. Sie ist damit das älteste, noch bestehende Fachmagazin für Fahrzeugtechnik der Welt. 1898 als „Der Motorwagen“ gegründet, werden hier von gestern bis heute Entwicklungen der Fahrzeug- und Motorentechnik publiziert. Gründungsmitglieder der Zeitschrift waren führende Ingenieure aus Deutschland, Europa und den USA.

Dazu gehörten, um nur einige zu nennen, Carl Benz, Gottlieb Daimler, Rudolf Diesel, Friedrich Lutzmann, Emil Rathenau, Edmund Rumpler, Emil Škoda, Ferdinand Graf von Zeppelin und Julius Springer, der unseren Verlag 1842 ins Leben rief. Seit 1939, dem Gründungsjahr der Schwesterzeitschrift MTZ Motortechnische Zeitschrift, widmet sich die ATZ exklusiv dem Gesamtfahrzeug.
1898 war technisch ein bewegtes Jahr: Ferdinand Braun führte den geschlossenen Schwingkreis ein. Pierre und Marie Curie entdecken das Radium und William Ramsay das Edelgas Xenon. Der brasilianische Motorflugpionier und Erfinder Alberto Santos-Dumont flog das erste von einem Benzinmotor angetriebene Luftschiff, und Ferdinand Graf von Zeppelin meldete das Patent für sein Starrluftschiff an. 1898 war auch das Gründungsjahr von Renault, Goodyear und der RWE. Und es war das Geburtsjahr des Daimler Phönix, des ersten Personenwagens mit Vierzylindermotor, ausgerüstet mit der über ein Jahr zuvor von Robert Bosch erfundenen Niederspannungs-Magnet-Zündung.

So manche Entwicklung davon durften wir in der ATZ vorstellen. Wir wünschen Ihnen viel Spaß bei der Lektüre der historischen und zeitgenössischen ATZ-Ausgaben in diesem Jubiläumsjahr.

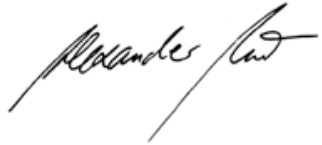

Dr. Alexander Heintzel Chefredakteur

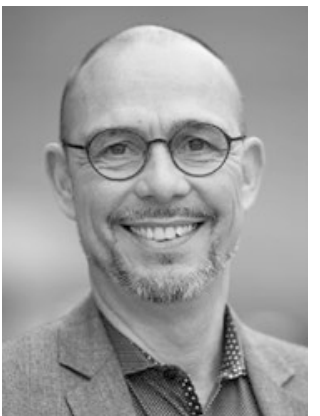

\section{Mincual Reide baul}

Dipl.-Ing. Michael Reichenbach Stellvertretender Chefredakteur

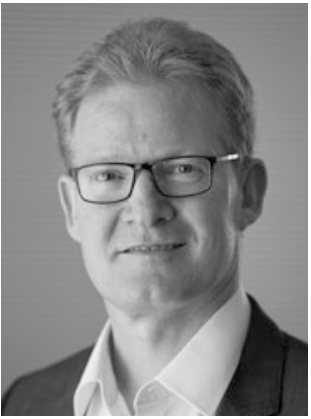

PS: Eine kleine Vorfreude für alle ATZ-Abonnenten: Zum Geburtstag drucken wir exklusiv die Erstausgabe des „Motorwagen“ von 1898 nach und legen sie der kommenden Februar-Ausgabe bei.

\section{Als Technologietreiber die automobile Zukunft mitgestalten}

Mit unseren Lösungen helfen wir als Technologieführer für den virtuellen Fahrversuch unseren Kunden weltweit realitätsgetreue virtuelle Tests im gesamten Entwicklungsprozess gemäß dem Prinzip des Automotive Systems Engineering durchzuführen und somit reale Prototypen einzusparen. 